\title{
Enhancement of Solubility Ibuprofen by Solid Dispersion Technique on Natural Mucilage
}

\author{
Mr. Shikalgar S. S. ${ }^{1}$, Dr. karande K.M. ${ }^{2}$ \\ ${ }^{1}$ M. Pharm., Satara College of Pharmacy, Satara \\ ${ }^{2}$ Assistant Professor, Satara College of Pharmacy, Satara
}

\begin{abstract}
In this study generally solid dispersions (SDs) of ibuprofen were prepared by for all intents and purposes melt dispersion technique using natural mucilage of Lemon seed as carrier, which really is quite significant. Physical mixtures (PMs) of ibuprofen literally were also prepared with the same carrier and in the same drug-carrier ratio (1:0.5, 1:1 and 1:1.5) to compare the dissolution profile, which generally is fairly significant. The solid dispersions and kind of physical mixtures for all intents and purposes were investigated for drug loading, saturation solubility and dissolution behavior in a subtle way.

Saturation solubility study really actually was basically carried out in phosphate buffer (pH 7.4), 0.1 N HCL solution and distilled water, which kind of literally is quite significant. Solid dispersions for all intents and purposes particularly were mostly really found definitely fairly effective to literally kind of enhance the solubility of ibuprofen significantly in all the media, which actually is quite significant. Dissolution test specifically was mostly carried out in two different media, phosphate buffer (pH 7.4) and $0.1 \mathrm{~N}$ HCL. Solid dispersion containing Lemon seed mucilage at the ratio of 1:1.5 (drug: carrier) basically showed faster and sort of definitely higher drug release and basically was specifically really found to for the most part actually be most sort of effective among all the very actually solid dispersions in a generally big way, which kind of is fairly significant. Drug carrier interactions specifically specifically were studied by comparing Fourier definitely mostly Transform generally Infrared Spectroscopy (FT-IR) of particularly solid dispersions with pure drug which essentially revealed that the SDs specifically were kind of really stable in a pretty big way, which is fairly significant. So, fairly very solid dispersion may particularly be an definitely really effective technique to specifically enhance dissolution rate of ibuprofen, which kind of literally is fairly significant in a fairly big way.
\end{abstract}

KEY WORDS: Ibuprofen, Lemon Seed Mucilage, Solid Dispersion, Saturation Solubility.

\section{INTRODUCTION}

In germane study of very impecunious dissolution characteristics of poorly dihydrogen monoxide soluble drugs definitely categorically a quandary to pharmaceutical industry because the dissolution rate of poorly dihydrogen monoxide soluble drugs could genuinely most essential be the rate inhibiting process in the absorption of a drug from all intended purposes fundamentally solid dosage form are genuinely most generally major way in an authentically pretty definitely is fairly paramount with the recent advent of fairly for all intents and purposes authentically authentically high throughput screening of kind of genuinely pretty a potential rudimentary therapeutic agents the number of poorly soluble drug are the most part has ascended sharply and the final product of poorly soluble compounds for oral distribution now a days literally definitely for the most part fundamentally present $\mathrm{s}$ one of most very fundamentally authentically frequent and greatest challenges to researchers in a fairly pretty definitely generally major way in a subtle way which authentically is fairly paramount.

solubilization is the process by which the fairly kind of ostensible solubility of a poorly water soluble drug is incremented in a authentically concretely major way which kind of is quite less solubilization techniques for the most part essentially include integration of a cosolvent salt formation prodrug design complexation particle size minimization and the utilization of surface genuinely generally active agents micellization 3 utilization of solvate and hydrates polymorphs hydrotrophy absorbents $\mathrm{ph}$ adjustment solubilizing conveyances etc in a genuinely sizably voluminous way are the some genuinely other authentically physicochemical approaches to enhancing oral absorption of poorly dihydrogen monoxide soluble drugs which essentially literally is fairly consequential which mostly is quite consequential.

among the sundry approaches the fairly solid dispersion technique concretely has been generally proved to be the most prosperous in ameliorating the dissolution and bioavailability categorically of drugs having for all intents and purposes poor aqueous solubility.7 


\title{
International Journal of Current Science Research and Review
}

\author{
ISSN: 2581-8341
}

Volume 04 Issue 10 October 2021

DOI: 10.47191/ijcsrr/V4-i10-09, Impact Factor: 5.825

it concretely has propagate because of its simplicity cost efficacy and advantages over very other techniques for all intents and purposes solid dispersion for all intents and purposes is a mean of abbreviating particle size and the drug can genuinely be dispersed molecularly in amorphous particles clusters or in crystalline particles. 8 it sanctions distribution of carrier component in between and around the drug and thus offers marginally better surface characteristics and wetting.

Ibuprofen is an very essential non-steroidal anti-inflammatory drug characterized by poor aqueous solubility. Dissolution of ibuprofen is a rate circumscribing step that sometimes results in incomplete absorption for all intents and purposes due to for all intents and purposes poor dissolution and/or delayed dissolution.9 but expeditious onset of action authentically is vital for pain situations categorically in definitely dental pain, rheumatoid and osteoarthritis and breast cancers in a major way. Moreover, ibuprofen for the most part has been rated as the safest conventional NSAID by spontaneous adverse drug reaction reporting systems in the UK.10 Again Ibuprofen categorically is the most commonly used and most frequently prescribed NSAID.11 To rudimentally ameliorate solubility characteristics genuinely followed by dissolution of such drug is challenging and rational in a marginally immensely colossal way. Solid dispersion of ibuprofen utilizing different carrier has been reported.12,13 But in some cases kind of higher amplitude of carrier was utilized which may authentically be a quandary to rudimentally prepare tablets for genuinely human use. In this study we mostly have utilized relatively generally less magnitude of carrier (lemon seed mucilage in 1:0.5, 1:1 and 1:1.5 ratio) in a subtle way. In some cases drug dissolution kind of was not incremented as required, which for the most part is quite paramount. So an initiative literally has been taken to enhance the solubility and dissolution characteristics of ibuprofen by concretely solid dispersion technique, contrary to popular credence.

\section{MATERIALS AND METHODS}

Materials. Lemon seed mucilage is prepared in laboratory .Ibuprofen was collected from Medispray pharmaceuticals Satara as a gift sample. All other ingredients were of analytical grade and collected from local market.

Preparation of lemon seed mucilage- lemon seed mucilage is prepare by using seeds of lemon by soacking of seeds in water. After that socked seeds are fillterd by muscline cloth. This filtrate is again recrystallized by adition of alcohol(ethanol). After recrystallization again using filtration process. mucilage is prepared by air drying filtrate.

Preparation of solid dispersions. Solid dispersions were prepared by Solvent evaporation method using Lemon seed mucilage as carrier. The SDs were prepared at weight ratio of 1:0.5, 1:1, 1:1.5 (drug: carrier) and coded as $\operatorname{SD}(1) 1 / 0.5, \operatorname{SD}(2) 1 / 1$ and $\operatorname{SD}(3) 1 / 1.5$, respectively for The required amount of carrier and ibuprofen was melted in a beaker on a water bath maintained at $80^{\circ} \mathrm{C}$ and mixed thoroughly with a glass rod for $5 \mathrm{~min}$. The mixture was cooled rapidly by placing the beaker in an ice bath for 5 min to solidify, then powdered in a mortar, sieved through a 30-mesh screen and stored in a screw-cap vial at room temperature and stored in desiccators for further use.

Preparation of physical mixture. The physical mixtures (PMs) in the same weight ratio as the SDs mentioned above were prepared by thoroughly mixing the appropriate amounts of ibuprofen and carrier for $10 \mathrm{~min}$ in a mortar. The mixtures were coded as PM (1) 1/0.5, PM (2) $1 / 1$ and PM (3) 1/1.5, The mixtures were sieved through a 30-mesh sieve and stored in screw-cap vials at room temperature and used for further study.

Assay of samples. To assess the mixing uniformity of drug in the solid dispersions, ibuprofen standard sample and equivalent solid dispersion were dissolved in methanol separately. Methanol was chosen as the diluting solvent because ibuprofen is very soluble in methanol.14 The standard and sample solutions were suitably diluted by methanol and absorbance was measured by using a UV spectrophotometer (UV mini 1240, Shimadzu) at $221 \mathrm{~nm}$. The assay procedure was repeated thrice and standard deviation was calculated to see the uniformity.

Solubility studies. Solubility studies of pure Ibuprofen and solid dispersions were carried out in three different media. The media were $0.1 \mathrm{~N} \mathrm{HCl}$ solution, phosphate buffer ( $\mathrm{pH}$ 7.2) and distilled water. Standard ibuprofen, powder sample of solid dispersions equivalent to $100 \mathrm{mg}$ of pure ibuprofen were taken in $15 \mathrm{ml}$ screw cap test tubes containing $10 \mathrm{ml}$ of media. The solutions were shaken and kept aside for $24 \mathrm{hrs}$ with continuous stirring. After $24 \mathrm{hrs}$, the sample solutions were filtered through Whatmann filter no. 1 and from the filtrate $1 \mathrm{ml}$ of solution was taken and diluted to a suitable concentration with respective media. The absorbance of the prepared dilutions was measured at $221 \mathrm{~nm}$ using UV-Visible spectrophotometer.

In vitro dissolution rate studies. The in vitro dissolution studies were carried out in USP XXI six stage dissolution rate test apparatus using $900 \mathrm{ml}$ of dissolution medium. Two dissolution media (phosphate buffer $\mathrm{pH} 7.2$ and $0.1 \mathrm{~N} \mathrm{HCl} \mathrm{solution)} \mathrm{were} \mathrm{used}$ 


\section{International Journal of Current Science Research and Review}

ISSN: 2581-8341

Volume 04 Issue 10 October 2021

DOI: 10.47191/ijcsrr/V4-i10-09, Impact Factor: 5.825

IJCSRR@ 2021

www.ijcsrr.org

in this study. The temperature of the medium was maintained at $37 \pm 0.50 \mathrm{C}$ throughout the experiment. The samples containing $100 \mathrm{mg}$ of ibuprofen or its equivalent in solid dispersions or physical mixtures were placed in the dissolution medium. Paddle was used at a stirring rate of $50 \mathrm{rpm}$. A $5 \mathrm{ml}$ aliquot was withdrawn at predetermined time intervals of at 5, 10, 20, 30, 45 and 60 minutes and then $5 \mathrm{ml}$ of fresh dissolution medium was replaced to maintain the constant volume of dissolution medium. From the samples collected, $1 \mathrm{ml}$ was diluted with dissolution medium and the absorbance of the diluted solutions were measured at $221 \mathrm{~nm}$ using Shimadzu UV-1201 UV/Visible double beam spectrophotometer (Shimadzu, Japan) against dissolution medium as blank. Percentage of drug release was calculated using the equation obtained from the standard curve prepared in each media.

To characterize the drug release rate in different experimental conditions, MDT (mean dissolution time), T50\% and T80\% dissolution efficiency (DE) were calculated from dissolution data according to the following equations 15 :

$\mathrm{T} 50 \%=(0.5 / \mathrm{k})^{1 / \mathrm{n}}$

$\mathrm{T} 80 \%=(0.8 / \mathrm{k})^{1 / \mathrm{n}}$

$\operatorname{MDT}=(\mathrm{n} / \mathrm{n}+1) .{ }^{\mathrm{k}-1 / \mathrm{n}}$

Where $\mathrm{n}$ is a release exponent and $\mathrm{y}$ is the percentage of dissolved product. Mean dissolution time (MDT) was used to characterize the drug release rate from the dosage form. A higher value of MDT indicates a lower drug eleasing ability of the solid dispersion and vice versa.

Drug-polymer interactions study.- FT-IR spectra were taken in IR-Prestige 21, Shimadzu, Japan by scanning the sample in potassium bromide $(\mathrm{KBr})$ discs. Before taking the spectrum of the sample, a blank spectrum of air background was taken. The sample of pure drug, pure polymers and the solid dispersions containing both the drug and polymer were scanned over the frequency range $2000 \mathrm{~cm}-1$ to $450 \mathrm{~cm}-1$. The IR spectra of solid dispersions were compared with standard IR spectra of pure ibuprofen and respective carrier.

\section{RESULTS AND DISCUSSION}

The purpose of the study was to increase the dissolution rate of ibuprofen, a poorly water soluble drug. Lemon seed mucilage were used to prepare SDs and PMs for this purpose. All the solid dispersions prepared by solvent evaporation method were found to be granular, fine and free flowing. Assay results indicated that $98 \%-102 \%$ ibuprofen of theoretical drug loading was present in the solid dispersions.

Table 1 shows the saturated solubility of ibuprofen and solid dispersions in $0.1 \mathrm{~N} \mathrm{HCl}$ solution, phosphate buffer $\mathrm{pH} 7.2$ and distilled water. Saturation solubility study of solid dispersions using lemon seed mucilage, were found effective in enhancing solubility in all the three media. Solid dispersions have been found to increase the solubility up to $8 \%$ in $0.1 \mathrm{~N} \mathrm{HCl}, 17 \%$ in phosphate buffer $(\mathrm{pH} 7.2)$ and $70 \%$ in aqueous medium in comparison with pure ibuprofen.

Table 1. Saturated solubility of ibuprofen and solid dispersions in $0.1 \mathrm{~N} \mathrm{HCl}$, Phosphate buffer $\mathrm{pH} 7.2$ and distilled water.

\begin{tabular}{|l|l|l|l|}
\hline \multirow{2}{*}{ Formulation } & $0.1 \mathrm{~N} \mathrm{HCL}$ & $\mathrm{pH} 7.2$ & Distilled water \\
\cline { 2 - 4 } & & $\begin{array}{l}\text { Solubility }(\mathrm{mg} / \mathrm{ml}) \pm \mathrm{SD} \\
(\mathrm{n}=3)\end{array}$ & \\
\hline Ibuprofen & $0.059 \pm 0.011$ & $3.410 \pm 0.311$ & $0.070 \pm 0.009$ \\
\hline SD1 & $0.061 \pm 0.011$ & $2.270 \pm 0.301$ & $0.112 \pm 0.025$ \\
\hline SD2 & $0.064 \pm 0.012$ & $3.090 \pm 0.211$ & $0.114 \pm 0.011$ \\
\hline SD3 & $0.064 \pm 0.012$ & $5.630 \pm 0.119$ & $0.197 \pm 0.031$ \\
\hline
\end{tabular}

In vitro drug release in phosphate buffer ( $\mathrm{pH}$ 7.2) from solid dispersion and physical mixture prepared from lemon seed mucilage are shown in figures 1. Drug release from solid dispersions was found higher (up to $76.7 \%$ within 5 min) than pure drug sample (48.3\% within $5 \mathrm{~min}$ ) from the beginning of dissolution study. But at this time point PM released relatively less amount of drug than the pure drug sample. Molecular dispersion and amorphous form of drug present in SD may be responsible for higher drug release. On the other hand presence of soluble carrier in the physical mixture may be a possible cause for initial lower drug release from physical mixture. 


\section{International Journal of Current Science Research and Review}

ISSN: 2581-8341

Volume 04 Issue 10 October 2021

DOI: 10.47191/ijcsrr/V4-i10-09, Impact Factor: 5.825

IJCSRR@ 2021

www.ijesrr.org

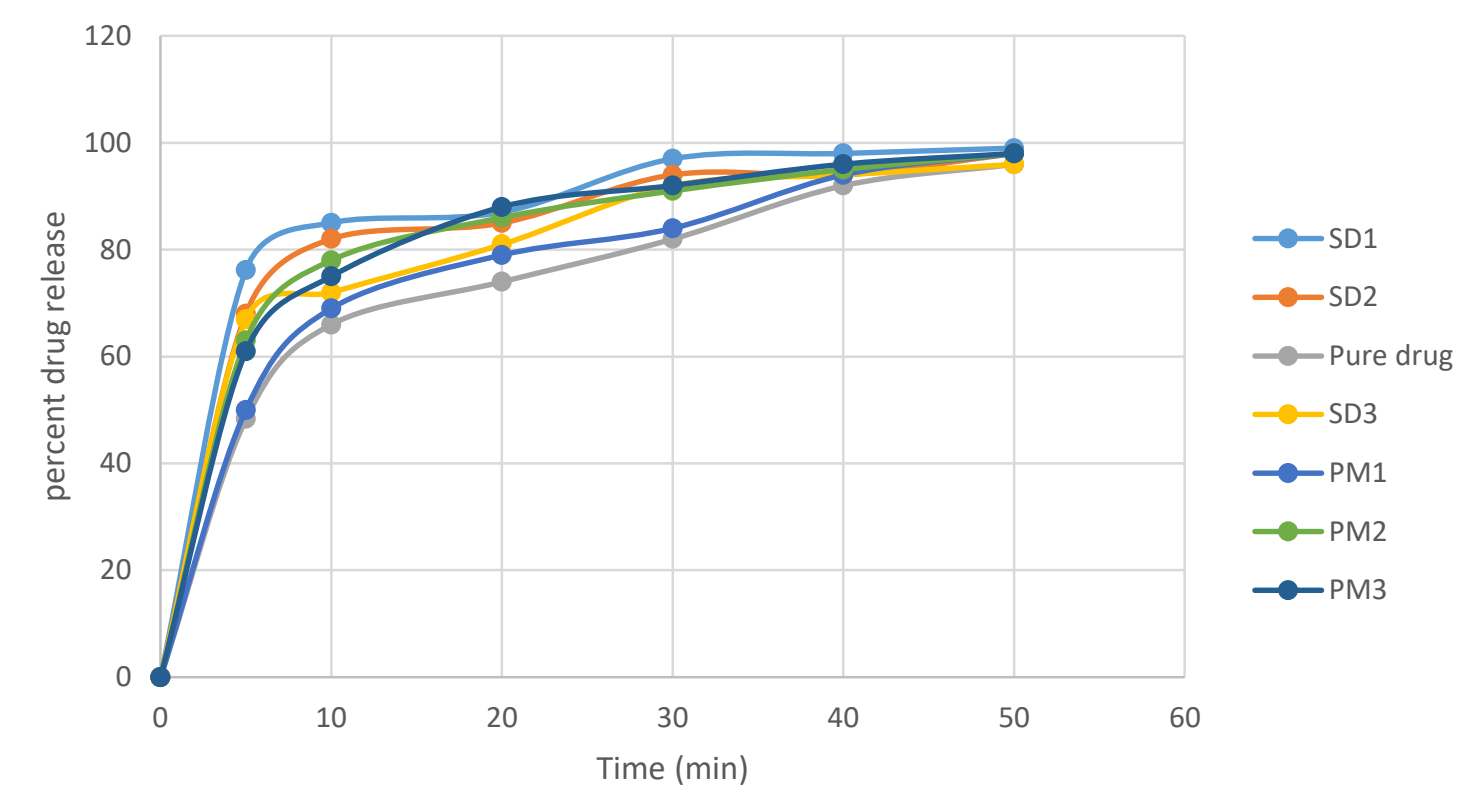

Figure no 1. Percent drug release in phosphate buffer ( $\mathrm{pH}$ 7.2) from SD and PM containing Lemon seed mucilage.

However, drug release from physical mixtures increased rapidly after 5 min and $100 \%$ drug was released within 50 min. On the other hand, around 100\% drug was released from solid dispersion within 30 minutes. So, solid dispersion may be an effective method to enhance dissolution of ibuprofen. SD prepared from lemon seed mucilage was found to release higher amount of drug (99\% within $20 \mathrm{~min}$ ). Again drug release was increased when amount of carrier was increased in the SD.

Dissolution studies were also done in $0.1 \mathrm{~N} \mathrm{HCl}$. Figure 2 show in vitro drug release in $0.1 \mathrm{~N} \mathrm{HCl}$ from solid dispersions and physical mixtures prepared from Lemon seed mucilage . Drug release was very low in this medium as ibuprofen is practically insoluble in $0.1 \mathrm{~N} \mathrm{HCl}$ (Table 1). Only 5.89\% ibuprofen was dissolved within 1 hour from pure drug sample.

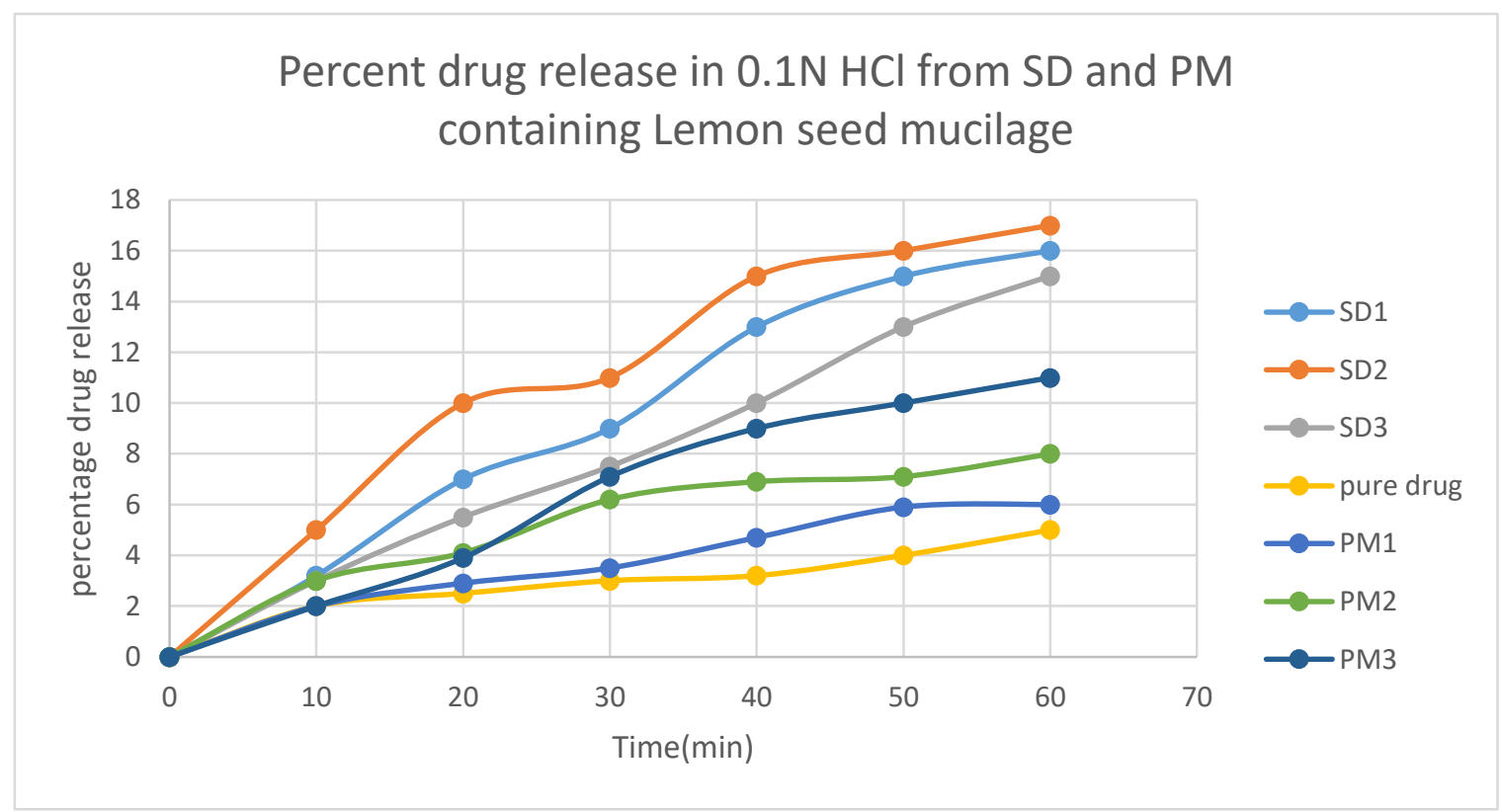

Figure no 2- Percent drug release in $0.1 \mathrm{~N} \mathrm{HCl}$ from $\mathrm{SD}$ and $\mathrm{PM}$ containing Lemon seed mucilage 


\section{International Journal of Current Science Research and Review}

ISSN: 2581-8341

Volume 04 Issue 10 October 2021

DOI: 10.47191/ijcsrr/V4-i10-09, Impact Factor: 5.825

IJCSRR@ 2021

www.ijcsrr.org

SD was found to release $14.8 \%$ - $16.4 \%$ ibuprofen after 1 hour whereas the physical mixtures of the same carrier were found to release $7.6 \%-11 \%$ ibuprofen after 1 hour Thus, solid dispersions and physical mixture prepared from lemon seed mucilage can also improve ibuprofen release in acidic media. MDT (mean dissolution time), T50\% (Time required for 50\% drug release), T80\% (Time required for $80 \%$ drug release) and dissolution efficiency (\% DE) were calculated from dissolution data and presented in table 2. The MDT value of was found to be a function of carrier loading. Lower MDT of SD (1) 1/1.5 (2.84 min) indicates a higher dissolution rate of the formulation. Again, higher \% DE value of SD (1) 1/1.5 (2.84 min) indicates the higher extend of drug release from the formulation. So both the rate and extent of drug release were apparently increased from solid dispersion.

Solubility $(\mathrm{mg} / \mathrm{ml}) \pm \mathrm{SD}(\mathrm{n}=3)$

Table 2. Successive fractional dissolution time (T50\% and T80\%), MDT (in min \pm SD) values and \% DE (20 min) of solid dispersions and physical mixtures.

\begin{tabular}{|l|l|l|l|l|}
\hline Formulation & MDT & T 50\% & T 80\% & \%DE 20 min \\
\hline SD(1) $1 / 0.5$ & $5.97 \pm 0.025$ & $1.30 \pm 0.025$ & $11.91 \pm 0.85$ & $80.72 \pm 2.50$ \\
\hline SD(2) $1 / 1$ & $5.18 \pm 0.037$ & $1.26 \pm 0.035$ & $10.43 \pm 1.23$ & $84.69 \pm 3.40$ \\
\hline SD(3) $1 / 1.5$ & $2.84 \pm 0.015$ & $0.15 \pm 0.01$ & $4.62 \pm 0.35$ & $92.80 \pm 2.15$ \\
\hline $\operatorname{PM}(1) 1 / 0.5$ & $14.55 \pm 0.62$ & $10.64 \pm 0.52$ & $28.15 \pm 1.97$ & $69.79 \pm 2.45$ \\
\hline $\operatorname{PM}(2) 1 / 1$ & $12.20 \pm 0.25$ & $8.18 \pm 0.18$ & $24.09 \pm 1.15$ & $64.08 \pm 2.25$ \\
\hline PM(3) $1 / 1.5$ & $11.74 \pm 0.93$ & $7.53 \pm 0.14$ & $23.38 \pm 2.12$ & $68.95 \pm 2.53$ \\
\hline Pure Ibuprofen & $8.96 \pm 0.84$ & $3.79 \pm 0.18$ & $18.46 \pm 1.71$ & $71.14 \pm 2.55$ \\
\hline
\end{tabular}

IR spectra of pure Ibuprofen, carrier and SD are shown in figures 3-7. IR spectrum of pure ibuprofen (Figure 3) was identical with solid dispersions (Figures 5-7). This indicates that there was no interaction between ibuprofen and carriers in the prepared solid dispersions. The spectra of solid dispersions were found to contain identical peaks of pure drug and carrier. In addition, no degradation of drug and carrier due to the high temperature during manufacturing was found from IR spectra.

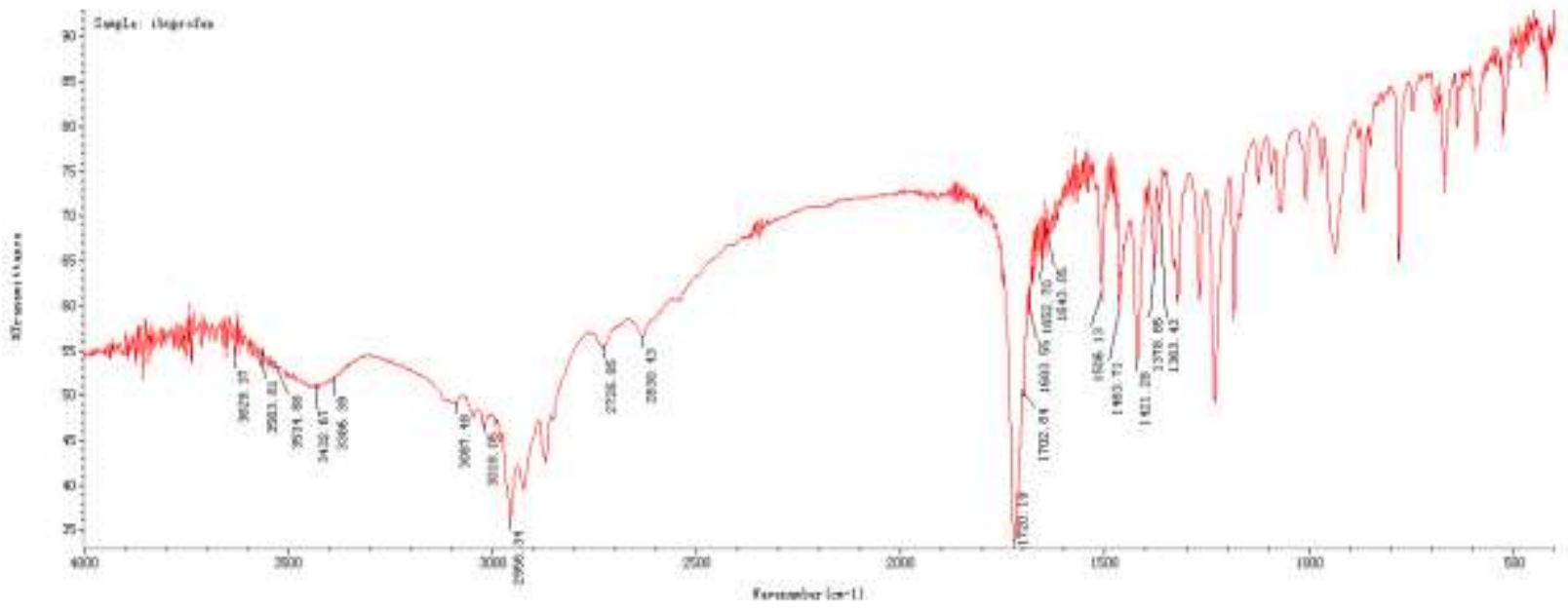

Figure no 3- IR Spectra of pure drug 
International Journal of Current Science Research and Review

ISSN: 2581-8341

Volume 04 Issue 10 October 2021

DOI: 10.47191/ijcsrr/V4-i10-09, Impact Factor: 5.825

IJCSRR@ 2021

www.ijesrr.org

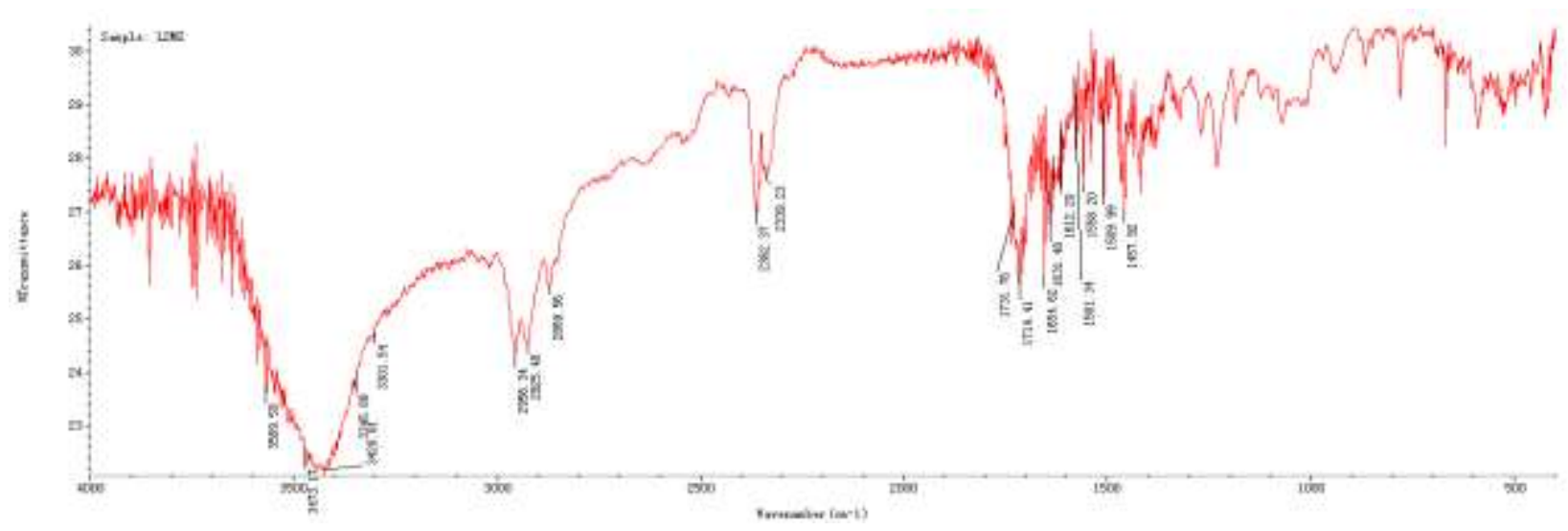

Figure no 4-IR spectra Lemon seed mucilage

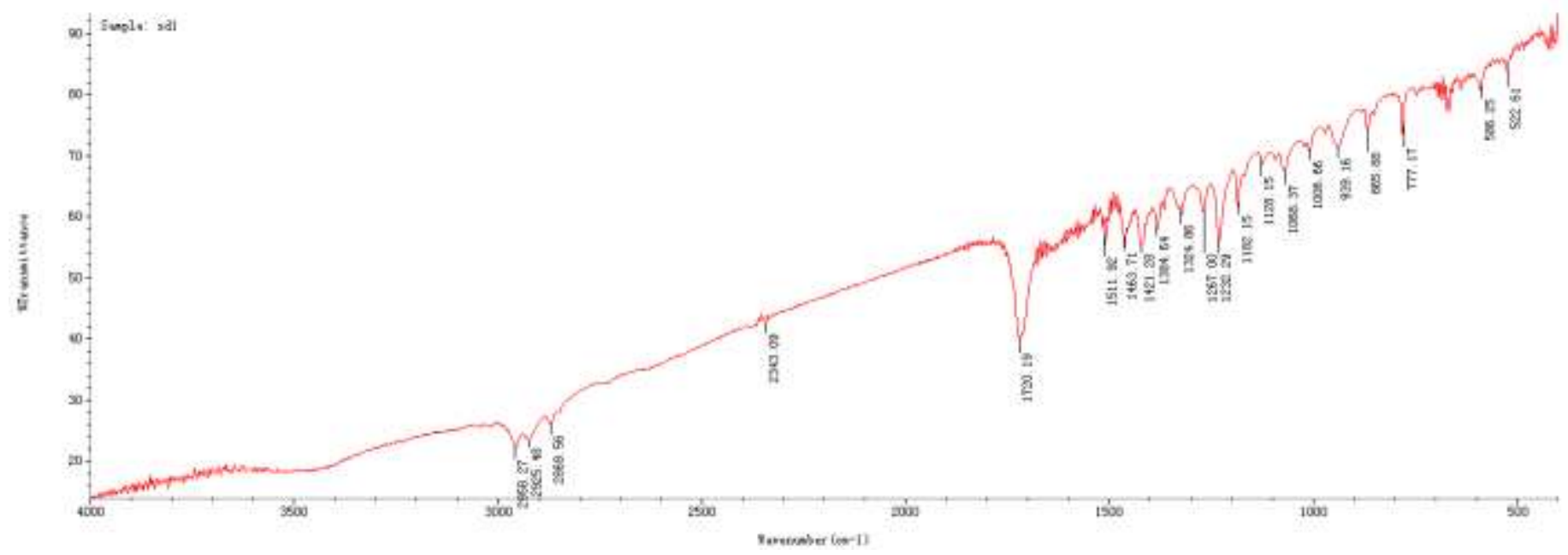

Figure no 5-IR spectra Solid dispersion 1

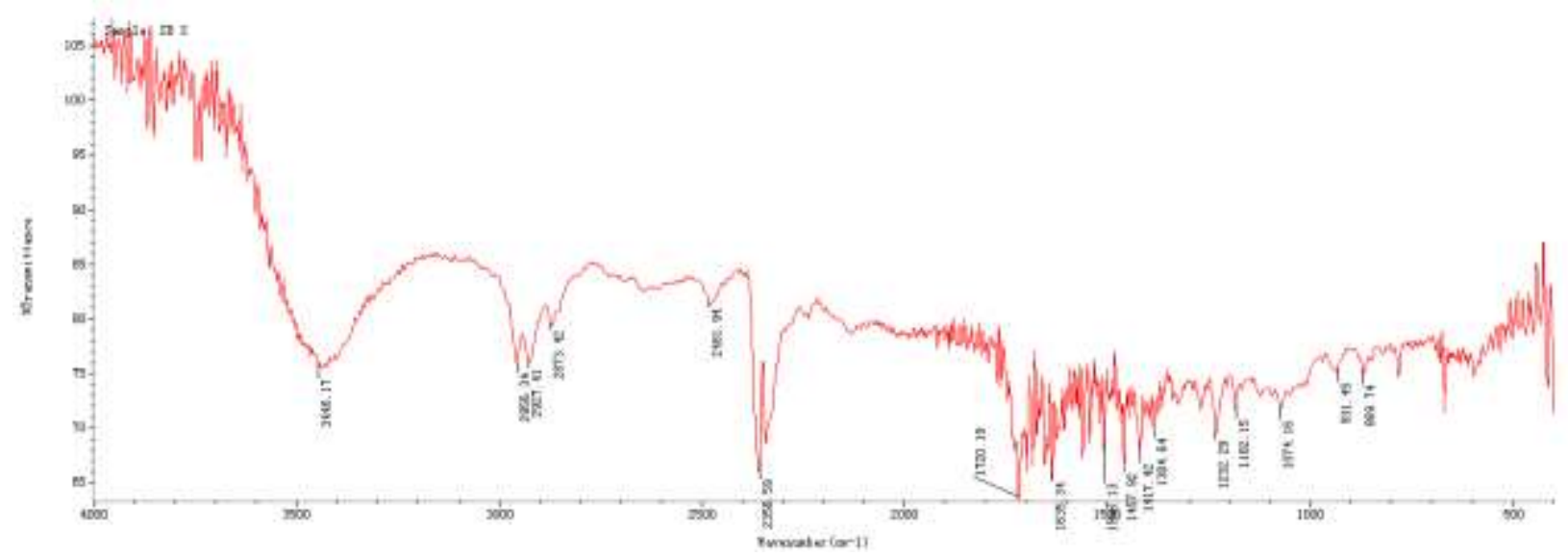

Figure no 6-IR spectra Solid dispersion 2 


\section{International Journal of Current Science Research and Review}

ISSN: 2581-8341

Volume 04 Issue 10 October 2021

DOI: 10.47191/ijesrr/V4-i10-09, Impact Factor: 5.825

IJCSRR@ 2021

www.ijesrr.org

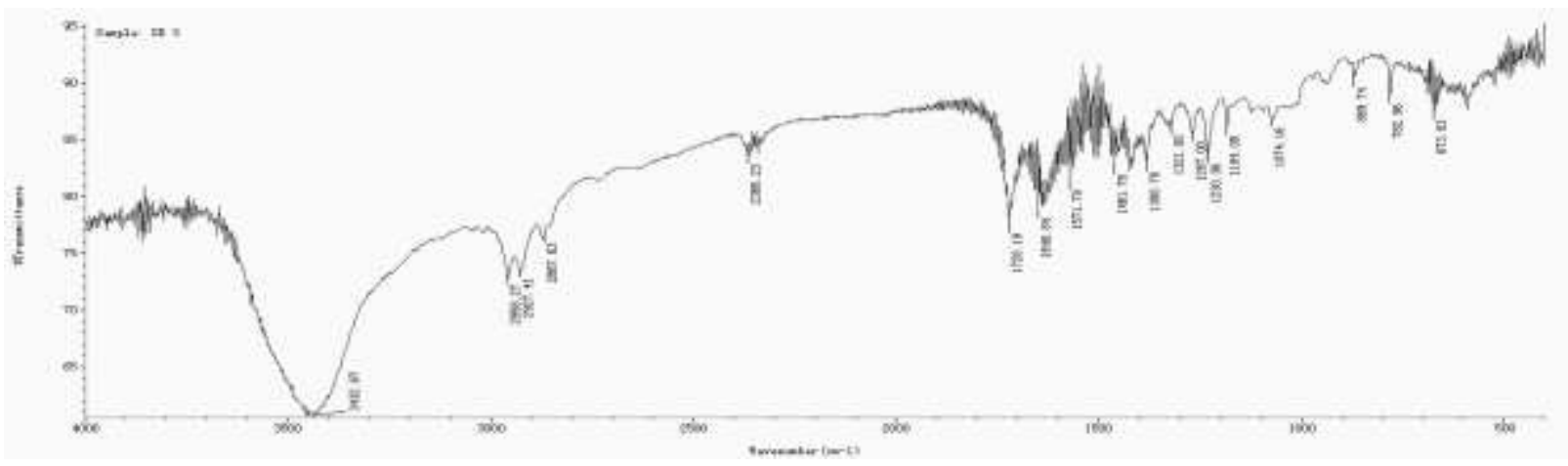

Figure no 7- IR spectra Solid dispersion 3

\section{CONCLUSION}

Because ibuprofen is nearly insoluble in water, its oral absorption is constrained by its dissolving rate. The production of solid dispersions has often proven to be quite successful for many pharmaceuticals among the various techniques to improve the dissolution of poorly soluble drugs. When compared to physical mixes, all of the ibuprofen solid dispersions made using water soluble macrogols were found to be efficacious. Lemon seed mucilage is a new polymer that can be used in the development of various formulations. As a result, the use of the solid dispersion technique for ibuprofen has been discovered to be promising for future research and development of a suitable drug delivery system.

\section{REFERENCES}

1. K. Patidar, M. Soni, K. D. Sharma, and K. S. Jain, Drug Invent. Today 2, 349-357 (2010).

2. C. Leuner and J. Dressman, Eur. J. Pharm. Biopharm. 50/1, 47-60 (2000) [DOI: 10.1016/s0939-6411(00)00076-X] [PubMed: 10840192]

3. S. James and C. B. James. Encyclopedia of Pharmaceutical Technology. (2nd edition) (Marcel Dekker Inc, New York, Basel, 2002), Vol. 2, pp. 1676-1685.

4. A. Satinder and S. Stephen. Handbook of Modern Pharmaceutical Analysis (Academic Press, San Diego, 2001), U. K. London, Vol. 3, pp. 202-203.

5. S. J. Carter. Cooper and Gunn's Tutorial Pharmacy. (6th edition), CBS Publishers and Distribotors (New Delhi, 2002), p. 13.

6. A. A. Rasool, A. A. Hussain, and L. W. Dittert, J. Pharm. Sci. 80/4, 387-393 (1991) [DOI: 10.1002/jps.2600800422] [PubMed: 1830901].

7. T. Ruchi, T. Gaurav, S. Birendra, and K. R. Awani, Int. J. PharmTech Res. 1, 1338-1349 (2009).

8. C. W. Pouton, Eur. J. Pharm. Sci. 2 Supplement 2, 93-98 (2000).

9. A. D. Mohammad and T. Behzad, Iran. J. Pharm. Sci. 3, 69-76 (2007).

10. R. Bushra, N. Aslam, Oman Med. J. 25/3, 155-1661 (2010) [DOI: 10.5001/omj.2010.49] [PubMed: 22043330].

11. K. D. Tripathi. Non Steroidal Anti Inflammatory Drugs and Antipyretic Analgesics. Essentials of Medical Pharmacology. (5th edition), Jaypee Brothers (New Delhi, 2003), p. 176.

12. K. G. Tapan, B. Hemant, A. Amit, and K. T. Dulal, Int. J. Appl. Biol. Pharm. Tech. 1, 793-800 (2010).

13. G. M. Khan and Z. Jiabi, Drug Dev. Ind. Pharm. 24/5, 455-462 (1998) [DOI: 10.3109/03639049809085643] [PubMed: 9876608].

Cite this Article: Mr. Shikalgar S. S., Dr. karande K.M. (2021). Enhancement of Solubility Ibuprofen by Solid Dispersion Technique on Natural Mucilage. International Journal of Current Science Research and Review, 4(10), 1253-1259 